\title{
Exploring the Socio-economic Implications of Artificial Intelligence from Higher Education Student's Perspective
}

\author{
Sarah Bamatraf ${ }^{1}$, Lobna Amouri ${ }^{2}$, Nahla El-Haggar ${ }^{3}$, Aishah Moneer ${ }^{4}$ \\ Computer Department, Imam Abdulrahman Bin Faisal University \\ Community College, Dammam, KSA
}

\begin{abstract}
As a result of the instability of oil prices, the economic prospects of the Gulf region are increasing their focus on new technologies. Thus, Saudi Arabia has demonstrated a strong commitment towards the development and implementation of Artificial Intelligence (AI) technologies as alternative sources for revenue and growth in line with globalisation, development, and the vision 2030. This paper examines the impact of AI in the Saudi Arabia community, especially for social and economic evolution. Special focus on the use of smart cars and smart cameras to monitor intelligently traffic, public services and national security is explored. A total of 424 participants from Eastern Province took part in this study. Analysis and discussion of the obtained results are also presented. The findings showed that $75.71 \%$ of participants mostly highly agreed about the AI economic impact leading to an increase in both government and business financial incomes. Whereas only $\mathbf{5 9 . 8 4 \%}$ of participants mostly highly agreed about the social impact of AI as they are worried about AI ethical concerns, job loss and the changing workforce.
\end{abstract}

Keywords-Artificial intelligence; Saudi community; data analysis; social efficiency impact; economic productivity impact

\section{INTRODUCTION}

AI is based on the use of big data, artificial learning and robot technology applications that will have far-reaching implications for the economy (Clark, 2020) [1], jobs, social fabrics and culture sectors (Elsaadani et al., 2018) [2]. For the last few decades, the energy sector's presence in the Saudi economy has decreased dramatically, from almost two-thirds of GDP to 43 percent by 2015 ((Elsaadani et al., 2018) [2] (Stephens et al., 2019) [3]). The Kingdom's government has responded with a series of contiguous strategies based especially on economic diversification that aimed to expand non-oil industries to ensure sustainable development, recruitment and to decrease the dependency of the public sector on jobs. According to Accenture analysis (Elsaadani et al., 2018) [2], the common point between all these strategies is the determined and exhaustive adherence to AI. This analysis demonstrated that AI has the capacity to considerably increase economic development rates by contributing $\$ 215$ billion in annual gross value added (GVA) to the economy of Saudi Arabia by 2035 . So far, the main idea beyond the Kingdom's
Vision 2030 national growth strategy is the technology sector (in government, business, services, industry, healthcare, education) which is rapidly empowered by AI. So far, the Traditional Economic Growth model shown in Fig. 1 demonstrates that capital, labour factors and new technologies are the key drivers of economic growth. Nevertheless, according to Accenture analysis, the new growth model treats AI as a new factor of economic growth rather than simply another technology-based productivity enhancer.

The objectives of the study are:

- To study the Saudi Arabia community's acceptance and willingness to deal with AI.

- To compare the future situation of Saudi Arabia's community in an AI scenario to a scenario without AI.

- To explore the AI impact on health, security, privacy (ethical considerations), safety, employment, education as well as public services of Saudi Arabia's population.

The remainder of this study is structured as follows: Section II explores a literature review about the implication of AI on social and economic development. Section III introduces the suggested methodology. Section IV clarifies the results and discussion. Finally, Section V illustrates conclusions, future work and limitations.

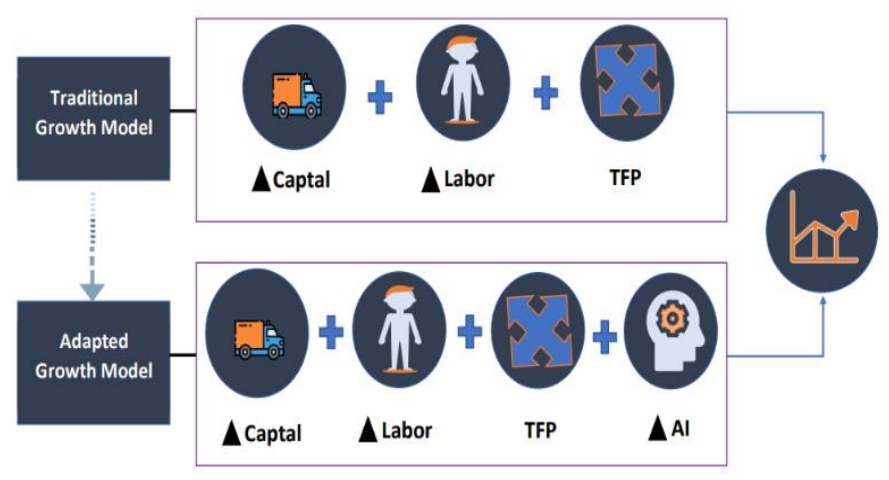

Fig. 1. Economic Growth Model (Elsaadani et al.,2018). 


\section{LITERATURE REVIEW}

This section present synthesizes the existing research papers that treated first with the AI applications for smart cities (smart cars and cameras). Then, we introduced a literature review on the social and economic AI implications at the national and international level.

\section{A. AI Applications in Smart Cities}

A. Beg, et al. (2020) [4] analysed transportation vulnerabilities and emergency response systems; proposed a smart, autonomous UAV-enabled solution; and demonstrated the system in a simulated environment. Various traffic control and police system conditions were taken into consideration in the simulation: traffic light abuses and accident detection, mobile speed traps and automatic alerts, crowds.

Impedovo, et al. (2020) [5] studied 21 peer-reviewed papers that contributed to the broad range of artificial intelligence applications and demonstrated that under a more resource-efficient management and economy than ordinary cities, smart cities work. As such, advanced business models around smart cities have grown, leading to the development of smart companies and organisations that rely on advanced technologies.

S. Hoofar, et al. (2020) [6] presented a new approach to supporting smart cars by exploring Vehicle Ad Hoc Networks (VANETs), which are intelligent interconnected vehicle networks that can provide real-time traffic parameters such as the type, speed, direction and location of each vehicle. The studied intelligent transport system is commonly used in various applications such as traffic flow control, automatic parking systems and security compliance.

\section{B. Social AI Impact}

The researchers in [7] demonstrated that AI has unfavourable effects on disadvantaged segments of populations, and the effects on individual AI applications can vary. Some other researchers in [8] examined what type of human labour will be a replacement versus a complement to emerging technologies in the field of AI. Besides, researchers in [9] studied the impacts of rapid progress in artificial intelligence technologies on society. They discussed one such potential impact: the issue of machine learning system accidents, identified as unintended and harmful actions that could result from poor design of real-world AI systems. Researchers in [10] have examined the effect of the use of AI in medicine at three levels. For clinicians, mainly by quick, precise interpretation of images; for health systems, through enhancing workflow and the ability to minimise medical errors; and for patients, through enabling them to access their own health-promoting data. They also argued the existing limitations of using AI in medicine including bias, privacy and security, and lack of clarity, along with the potential directions for these applications. While researchers in [11], [12] [13], [14] and [15] used AI to build various systems for people with disabilities and aged persons who require support in their everyday lives or in recovery from emergency situations.

The proposed systems identified vital signs (Body Temperature, Blood Pressure, Blessing, Heart Pulse Rate, and Consciousness) as well as location/attitude monitored by the sensor network. Besides, researchers in [16] focused on AIbased learning by trying to analyse and investigate how AI can be fruitfully exploited by universities in Saudi Arabia. In addition, they centralised on challenges of teaching/learning procedure and advantages in the implementation of Information and Communication Technologies (ICT) in a classroom, leading to delegate an academic committee to an AI-based context. The researchers in [17] created a short questionnaire and circulated it to four expert groups in $2012 / 2013$. For instance, they detected that there was, in some areas, concern over high-level artificial intelligence growing up in a few decades and addressing its serious dangers for humanity. In other areas, these concerns have been overlooked or deemed science fiction, what the likelihood that the best experts allocated to high-level machine intelligence coming up within a given time frame, which threats they have seen in this growth, and how rapidly they have seen them evolve.

\section{Economic AI Impacts}

Approximately $47 \%$ percent of the all jobs in the U.S. are at risk from computerisation, according to Frey and Osborne (2013) [18]. Author (2015) [19] argues, however, that automation and technological advancement have not led to the obsolescence of human labour. Automation and labour are highly complementary, particularly for staff who are adaptable, innovative, and solution oriented.

E. Ernest, et al. (2019) in [20] demonstrated how AI has produced widespread worry of job loss and further increases in unfairness. The authors called, through the paper, for a reasonable outlook on the opportunities and risks from AI. For this, they discussed how skills policies and new ways of digital economy regulation are necessary to prevent further increases in market concentration, ensure adequate data protection and privacy and help redistribute the gains of productivity growth by combining wealth sharing, capital taxes and a decline in working time.

On the other hand, G. C. Allen (2019) in [21] addressed China's political thinking towards AI and national security and highlighted that China's leadership claims that being at the forefront of AI technologies is vital to the future of global military and economic-power rivalry.

M. Uzun (2020) in [22] addressed growing awareness about the negative impacts of AI among countries and proposed a solution modelling universal norms, international institutions and policies that ensure beneficial discovery of AI in order to provide a strategic equilibrium between major powers, international economic stability, and equitable economic control at national and international levels. Besides, O. Hassan (2020) in [23] described how the new mega-city Neom, currently under construction in Kingdom of Saudi Arabia, is targeting to integrate robotics and AI into various aspects of citizens' lives in order to generate earnings from key economic sectors for the future. The authors discussed also that this transition from an economy based on oil to AI targets to secure the survival of the Saudi community and meet the growing challenges of constructing a state around oil. 


\section{METHODOLOGY}

This current study was prepared at the Computer Department of the Community College of Dammam, which is a college in Imam Abdulrahman Bin Faisal University that provides diploma graduates for both female and male students. All participants that took part in questionnaires answered closeended items which are likely to receive short answers. A Likert scale which is a close-ended, forced-choice scale is used in the questionnaire to provide a series of answers. This study used a 4-point Likert scale ranging from S.A (Strongly Agree), A (Agree), D (Disagree) and S.D (Strongly Disagree) to explore the participants' acceptance and willingness to deal with AI. Six criteria were used to develop the questionnaire including acceptance, security, ability, increase productivity, approval, and efficiency. A set of items were prepared for each domain according to five demographic profile items given at the beginning of the questionnaire. The demographic profile items include gender, identity, age-category, education, and standard of living. Besides, the conducted questionnaire explores the effect of specific AI applications in Saudi Arabia on social and economic developments. As well as, AI applications were discussed that include utilising smart cars and smart cameras for intelligent monitoring of traffic, public services, and national security.

\section{A. Participants}

A total of 424 participants took part in the questionnaire. The participants include students and teachers of Imam Abdulrahman Bin Faisal University, some other faculty members and employees in public and private sectors working outside the university. The groups we asked were categorised referring to the following criteria:

- Gender: Male or female.

- Identity: Saudi, non-Saudi.

- Age-Category: from 15 to 34 years, from 35 to 60 years.

- Education: High School Degree, Undergraduate Degree, Postgraduate Degree.

- Standard of living: Low, Moderate, High.

\section{B. Data Collection}

The conducted questionnaire is a cross-sectional one as collecting information from the respondents was conducted over a single period which was from 28 of February 2020 to 6 March 2020. It was prepared using the Google Forms tool and shared with participants by means of a link (see Appendix A). The sharing process took advantage of the best mobile messaging applications like WhatsApp, Viber, Snapchat and Facebook messenger that offer a superior substitute to email and text messaging thanks to built-in social networking characteristics and improved security. The questionnaire was appropriately configured to describe the views, concerns, obstacles and ideas of the participants in order to identify the measures needed to further strengthen the actual condition of AI in Saudi Arabia.

\section{Data Analysis}

Several steps were taken to analyse the data. Data was collected in an excel file and pictures were sorted out; percentages of the answers were calculated and studied thoroughly. The percentage for each item was determined using the mathematical formula 1, out of a total of 424 respondents who answered the questionnaire.

$S_{i, j}=\frac{\text { Frequency of answers in each } \text { scale }_{i, j}}{\text { Total number of respondents }} * 100$

Where $\mathrm{i}$ is the number of items from $1,23,4 \ldots 16$ and $\mathrm{j}$ is the number of scales from 1 to 4 . Note that the scale number 1 refers to scale Strongly Agree (S.A), 2 refers to Agree (A), 3 refers to Disagree (D) and 4 refers to Strongly Disagree (S.D).

The mean score $(\mathrm{Mi}, \mathrm{j})$ was also calculated for each item, to describe the strength of each one. In fact, weights (w) were assigned for each Likert scale. The larger number (4) was assigned to the most positive scale (S.A), 3 was assigned to (A), 2 to (D) and 1 to (S.D). The standard deviation was then applied to estimate the dispersion of each item relative to its mean. In fact, a second mean (M 0i,j) with the newest weights (W) $(1,4,9$ and 16) was explored to calculate the standard deviation STDEVi,j. The mathematical formula 2, 3 and 4 represents respectively the first mean $(\mathrm{Mi}, \mathrm{j})$, the second mean (M 0i,j) and Standard Deviation STDEVi,j:

$M_{i, j}=\sum_{i, j} S_{i, j} * w_{1} ; \mathrm{w} 1=\mathrm{wj}=4,3,2,1$

$M 0_{i, j}=\sum_{i, j} S_{i, j} * w_{2} ; \mathrm{w} 2=\mathrm{wj} 2$

$\operatorname{STDEV} V_{i, j}=\sqrt{M 0_{i, j}-M_{i, j}^{2}}$

Respectively, the mean score (Mc) and the standard deviation STDEVc were also calculated for each criterion c, where $\mathrm{c}$ is from 1 to 6 as shown in formulas 5 and 6 . Then we used equations the formulas 7 and 8 to calculate the mean score (Md) and the standard deviation STDEVd for each domain is d, where $\mathrm{d}$ is from 1 to 2 .

$M_{c}=\frac{\sum M_{i, j} \text { for each criterion }_{c}}{\text { Number of items for each criterion }}$

$S T D E V_{c}=\frac{\sum S T D E V_{i, j} \text { for each criterion }}{c}$

$M_{d}=\frac{\sum M_{c} \text { for each domain }_{d}}{\text { Number of criterion for each domain }}$ do $_{d}$

$S T D E V_{d}=\frac{\sum S T D E V_{c} \text { for each domain }}{d}$

\section{RESUlTS AND DISCUSSION}

This section demonstrates and recognises the beneficial effects of adopting AI on the social domain and on specific criteria such as acceptance, security, ability, approval and efficiency. In addition, it identifies the advantages of AI in the economic domain to find out its effect on increasing the competitiveness of the Saudi community by using smart cars as well as implementing AI in working areas (companies, universities, hospitals...) to explore factors influencing the Saudi community's satisfaction with AI. 


\section{A. Demographics Profile Results}

Table I shows the results of the questionnaire's items regarding respondents' demographic profile where the size of the sample is 424 Saudi community members. The demographic results signify $85 \%$ of the respondents to be female while $15 \%$ were male respondents. This can be explained by the fact that the college was originally a girl's college, and the boy's branch has recently been added, in addition to the lack of awareness between the sexes about the impact of artificial intelligence on society. According to the item "Age-Category", most of the respondents (373 or $88 \%$ ) of the sample population fall with $15-34$ years category while 51 respondents were between 35-60 years, representing $12 \%$ of the total sampled population. As for the item "Education", the majority of the respondents (260 or 61\%) have an Undergraduate Degree and 157 (37\%) respondents have Postgraduate Degree. The remaining $7(2 \%)$ of the total sampled population have a High School Degree. As for the item "Standard of Living", most of the respondents (336 or $79 \%$ ) have a Moderate Standard of Living, 73 of the respondents have a High Standard of Living representing $(17 \%)$, and 15 of the respondents have a Low Standard of Living representing $4 \%$ of the total sampled population.

TABLE I. RESPONDENTS' DEMOGRAPHIC PROFILE

\begin{tabular}{|l|l|l|l|}
\hline $\begin{array}{l}\text { Demographic } \\
\text { Information's }\end{array}$ & Options & Frequency & $\begin{array}{l}\text { Percentage } \\
(\%)\end{array}$ \\
\hline Gender & Male & 63 & 15 \\
& Female & 361 & 85 \\
\hline Identity & Saudi & 348 & 82 \\
& Non-Saudi & 76 & 18 \\
\hline \multirow{2}{*}{ Age-Category } & $15-34$ & 373 & 88 \\
& $35-60$ & 51 & 12 \\
\hline \multirow{3}{*}{ Education } & High School Degree & 7 & 2 \\
& Undergraduate Degree & 260 & 61 \\
\hline \multirow{2}{*}{$\begin{array}{l}\text { Standard of } \\
\text { Living }\end{array}$} & Postgraduate Degree & 157 & 37 \\
& Mow & 15 & 4 \\
& High & 336 & 79 \\
\hline
\end{tabular}

\section{B. Analytical AI Impacts on Social and Economic Domains} based on Item

The conducted questionnaire is a cross-sectional one as the collection information from the respondents was conducted over a single period of time, which was from 28 of February 2020 to 06 March 2020. It was prepared using the Google Forms tool and shared with participants by means of a link. The sharing process took advantage of the best mobile messaging applications like WhatsApp, Viber, Snapchat and Facebook messenger that offer a superior substitute to email and text messaging thanks to built-in social networking characteristics and improved security. The questionnaire was appropriately configured to describe the views, concerns, obstacles and ideas of the participants in order to identify the measures needed to further strengthen the actual condition of AI in Saudi Arabia.

Table II provides the analytical breakdown of the impacts of AI on social and economic domains on the Saudi community. Also, it illustrates the feedback obtained from respondents regarding the social and economic criteria factors affecting the satisfaction of the AI Saudi community.

There are 14 items for the social domain classified as 6 items for acceptance, 2 items for security, 3 items for ability, 2 for approval, and 1 item for efficiency. Also, there are 2 items for the economic domain that examine the productivity criterion. The mean score for each item was used to describe the strength of each one. In the social domain, there are 4 items' mean scores higher than 3 and 1 item for the economic domain. The obtained result demonstrates that some respondents highly agree about the impact of AI on security, approval, efficiency and productivity items.

Furthermore, 9 items' mean scores are higher than 2 in the social domain and 1 item in the economic domain. Thus, most respondents mostly agree about the impact of AI on acceptance, security, ability and approval' items. On the other hand, there is only 1 item's mean score lower than 2 in the social domain in relation to being photographed without people's knowledge. The result could be explained by the fact that the Saudi community is so far considered as conservative families. Fig. 2 and 3 provides the graphical interpretation of the information provided in Table II.

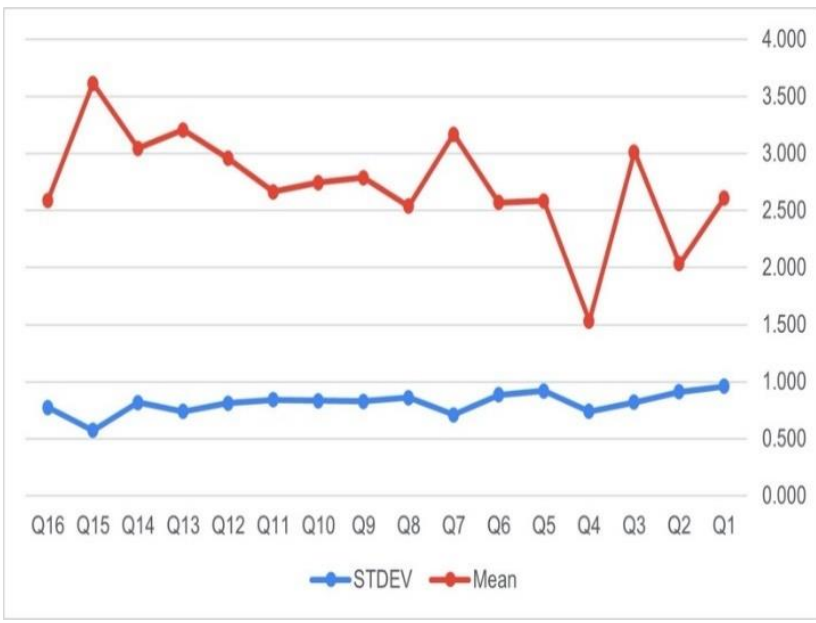

Fig. 2. Means and Standard Deviation for each Item.

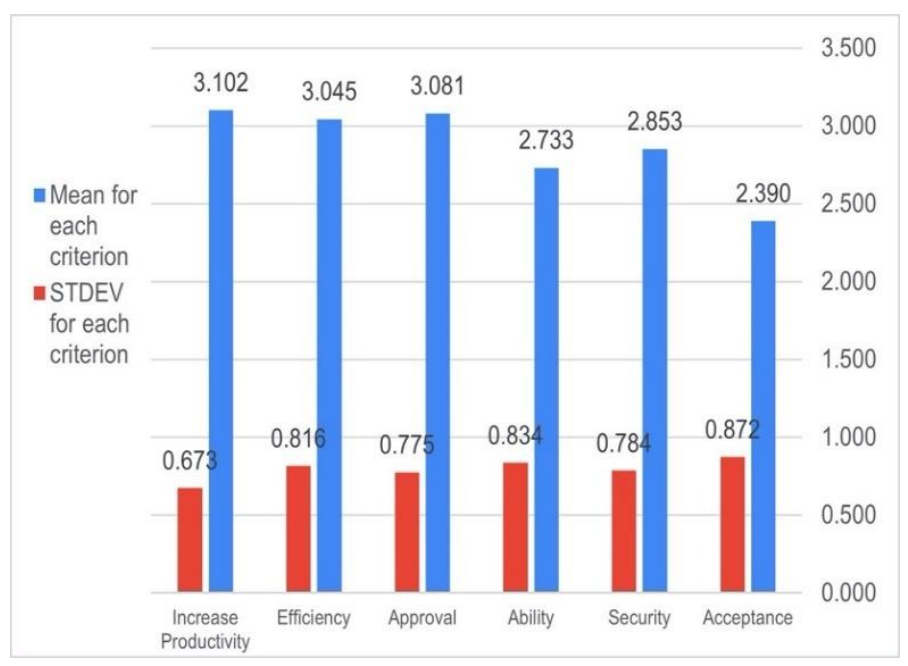

Fig. 3. Means and Standard Deviation for each Criterion. 


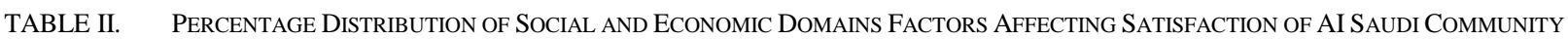

\begin{tabular}{|c|c|c|c|c|c|c|c|c|}
\hline Domain & Criteria & Items & S.A\% & $\mathrm{A} \%$ & $\mathrm{D} \%$ & S.D\% & $\mathrm{Mi}$ & STDEVi \\
\hline \multirow{15}{*}{ 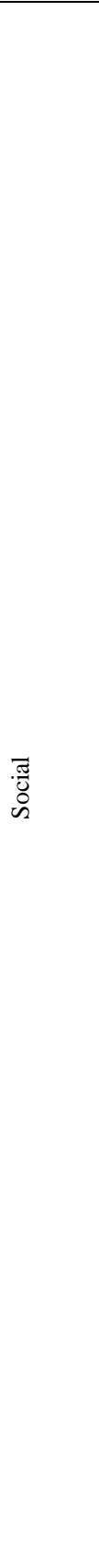 } & \multirow{6}{*}{ Acceptance } & $\begin{array}{l}\text { 1.Do you accept to be controlled by } \\
\text { smart cameras while shopping, } \\
\text { driving, walking, getting a public } \\
\text { service (bank, ministry, school, } \\
\text { university, hospital? }\end{array}$ & 19.1 & 37.97 & 27.83 & 15.09 & 2.611 & 0.960 \\
\hline & & $\begin{array}{l}2.7 \text { o you accept that your personal } \\
\text { information will be saved including } \\
\text { your face patterns, your actions, } \\
\text { your movements, your car number? }\end{array}$ & 8.49 & 17.69 & 42.45 & 31.37 & 2.033 & 0.911 \\
\hline & & $\begin{array}{l}\text { 3.Do you think that using smart } \\
\text { cameras could increase the } \\
\text { efficiency of social } \\
\text { services (like booking ticket using } \\
\text { face patterns only in airports? } \\
\end{array}$ & 28.77 & 49.06 & 16.75 & 5.42 & 3.012 & 0.82 \\
\hline & & $\begin{array}{l}\text { 4.Do you accept to be photographed } \\
\text { without your knowledge }\end{array}$ & 3.07 & 5.66 & 32.55 & 58.73 & 1.531 & 0.739 \\
\hline & & $\begin{array}{l}\text { 5.Do you accept being surveyed } \\
\text { almost completely by government } \\
\text { authorities? }\end{array}$ & 15.75 & 41.75 & 28.07 & 14.62 & 2.583 & 0.92 \\
\hline & & $\begin{array}{l}\text { 6.Do you accept boarding in a smart } \\
\text { car and not driven by a human } \\
\text { being? }\end{array}$ & 15.09 & 38.68 & 34.43 & 11.79 & 2.571 & 0.885 \\
\hline & \multirow{2}{*}{ Security } & $\begin{array}{l}\text { 1.Do you think that using smart cars } \\
\text { in Saudi Arabia is much secure than } \\
\text { traditional driving? }\end{array}$ & 31.84 & 56.13 & 8.96 & 3.07 & 3.167 & 0.709 \\
\hline & & $\begin{array}{l}\text { 2.Do you think that using smart } \\
\text { surveillance cameras in Saudi } \\
\text { Arabia could release a secure life } \\
\text { better than your actual life? }\end{array}$ & 14.62 & 234.43 & 41.04 & 9.91 & 2.538 & 0.86 \\
\hline & \multirow{3}{*}{ Ability } & $\begin{array}{l}\text { 1.Do you think that the smart car is } \\
\text { better than human being driver? }\end{array}$ & 19.1 & 47.41 & 26.65 & 6.84 & 2.788 & 0.828 \\
\hline & & $\begin{array}{l}\text { 2.Do you think that using smart cars } \\
\text { will reduce the accident rate in } \\
\text { Saudi Arabia? }\end{array}$ & 20.52 & 38.21 & 36.56 & 4.72 & 2.745 & 0.833 \\
\hline & & $\begin{array}{l}\text { 3.Do you think that smart cameras } \\
\text { are able to work continuously } \\
\text { (while raining, winding, a } \\
\text { troubleshoot in electrical power)? }\end{array}$ & 17.45 & 38.44 & 37.26 & 6.84 & 2.665 & 0.842 \\
\hline & \multirow{2}{*}{ Approval } & $\begin{array}{l}\text { 1.Do you agree about using artificial } \\
\text { intelligence generally in Saudi } \\
\text { Arabia }\end{array}$ & 26.42 & 47.41 & 21.7 & 4.48 & 2.958 & 0.812 \\
\hline & & $\begin{array}{l}\text { 2.Do you think that the advantages } \\
\text { of artificial intelligence are more } \\
\text { than its disadvantages? }\end{array}$ & 36.08 & 51.89 & 8.49 & 3.54 & 3.205 & 0.738 \\
\hline & Efficiency & $\begin{array}{l}\text { 1.Do you think that smart cameras } \\
\text { will collect data efficiently? }\end{array}$ & 31.6 & 45.28 & 19.1 & 4.01 & 3.045 & 0.816 \\
\hline & \multicolumn{2}{|c|}{ Total Distribution for Each Scale } & 20.55 & 39.29 & 27.27 & 12.89 & & \\
\hline \multirow{3}{*}{ 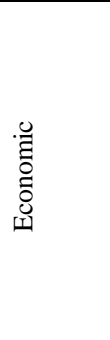 } & \multirow[b]{2}{*}{ Increase Productivity } & $\begin{array}{l}\text { 1.Do you think that using smart } \\
\text { cars increases people's } \\
\text { productivity? }\end{array}$ & 64.62 & 33.02 & 0.94 & 1.18 & 3.615 & 0.572 \\
\hline & & $\begin{array}{l}\text { 2.Do you think that using smart } \\
\text { cameras in working areas } \\
\text { (companies, universities, } \\
\text { hospitals...) could increases } \\
\text { employee's productivity? }\end{array}$ & 11.56 & 42.22 & 39.86 & 6.37 & 2.59 & 0.775 \\
\hline & \multicolumn{2}{|c|}{ Total Distribution For Each Scale } & 38.09 & 37.62 & 20.4 & 3.77 & & \\
\hline
\end{tabular}




\section{Analytical AI Impact for each Social Criterion}

- Generally, the research found that the total respondents mostly agreed the AI social impact is $59.84 \%$ which is the sum of S.A $(20.55 \%)$ and A $(39.29 \%)$. This result will be detailed below among different social criteria.

Acceptance criteria: The research found that the Saudi community (the respondents) agreed most highly upon item 3 that using smart cameras could increase the efficiency of social services (like booking tickets using face patterns only in airports had an average of $m=3.12(\mathrm{STDEV}=0.82)$. The most commonly agreed upon acceptance of controlling by smart cameras while shopping, driving, walking, getting a public service (bank, ministry, school, university, hospital had an average of $\mathrm{m}=2.611$ (STDEV $=0.960$ ) and monitoring and tracking the personal information and behaviour without knowledge) had an average of $\mathrm{m}=2.39$ (STDEV $=0.872$ ). Also, the most commonly agreed upon approval of completely surveyed by government authorities, showed an average of $\mathrm{m}=$ 2.583 (STDEV = 0.92). Onboarding in a smart car and not driven by a human being, had an average of 2.571 (STDEV = 0.885 ) and the agreement of saving the extracting personal features which include face patterns, actions, movements and car number, showed an average of $\mathrm{m}=2.033$ (STDEV=0.911).

- Security criteria: The research found that the Saudi community agreed most highly upon item 1 with an average for using smart cars being much secure than traditional driving with an average of $\mathrm{m}=3.167$ ( STDEV=0.709). They mostly agreed upon item 2 with an average $\mathrm{m}=2.538$ (STDEV=0.86) for using smart surveillance for cameras in Saudi Arabia to release a secure life better than your actual life.

- Ability criteria: The research found that the Saudi community mostly agreed upon item 1 with an average of $\mathrm{m}=2.788$ (STDEV=0.828) for the ability of the smart car to do better than a human being driver. They mostly agreed upon item 2 with an average of $\mathrm{m}=2.745$ $(\mathrm{STDEV}=0.833)$ for the ability to use smart cars to reduce the accident rate in Saudi Arabia. Also, they mostly agreed upon item 3 with an average of $m=2.665$ $(\mathrm{STDEV}=0.812)$ for the ability of smart cameras to work continuously (while raining, winding, a troubleshoot in electrical power).

- Approval criteria: The research explored that the Saudi community agreed most highly upon item 2 with an average of $\mathrm{m}=3.205$ (STDEV $=0.738$ ) for approving that the artificial intelligence has a great advantages on Saudi society more than its disadvantages and they mostly agreed upon item 2 with an average of $\mathrm{m}=2.958$ (STDEV=0.812) for utilising artificial intelligence generally in Saudi Arabia.

- Efficiency criteria: The research revealed that the Saudi community agreed most highly upon item 1 with an average of $\mathrm{m}=3.045 \quad(\mathrm{STDEV}=0.816)$ for the efficiency of using smart cameras for collecting data for approving that artificial intelligence has great advantages on Saudi society more than its disadvantages. They mostly agreed upon item 2 with an average of $\mathrm{m}=2.958$ (STDEV=0.812) for utilising artificial intelligence generally in Saudi Arabia.

\section{Analytical AI Impact for Economic Criterion}

- Increasing Productivity: The research found that the Saudi community agreed most highly with an average of $\mathrm{m}=3.615$ (STDEV=0.572) for increasing people's productivity by using smart cars. They mostly agreed upon item 2 with an average of $m=2.59(0.775)$ for increasing employee's productivity by using smart cameras in working areas (companies, universities, hospitals, etc.). Thus, the total respondents that agreed most highly the economic AI impact is $75.71 \%$ which is the sum of S.A (38.09\%) and A (37.62\%).

\section{E. Overview of AI Impact on Domains}

In Table III, generally, the research found that the Saudi community agreed most highly about the impact of AI upon the economic domain and specifically for the criteria "increasing people's productivity" by using smart cars and implementing AI in working areas (companies, universities, hospitals...) with the total average $\mathrm{m}=3.102$ (STDEV=0.673). Besides, the research found that the Saudi community mostly agreed with the impact of AI on the social domain, with the total average $\mathrm{M}=2.82$ ( $\mathrm{STDEV}=0.816$ ). Specifically, for each criterion of the social domain, the respondents agreed most highly about the impact of AI upon the approval representing a total average of $\mathrm{m}=3.081(\mathrm{STDEV}=0.775)$ and upon the efficiency criteria of using smart cameras for collecting data with a total average $\mathrm{m}=3.045 \quad(\mathrm{STDEV}=0.816)$. The respondents most commonly agreed on the impact of AI upon the security that represents a total average $\mathrm{m}=2.853$ (STDEV= 0.784 ), upon ability representing the total average of $\mathrm{m}=2.733$ $(\mathrm{STDEV}=0.834)$, and acceptance representing the total average $m=2.39(\mathrm{STDEV}=0.872)$. Furthermore, Fig. 5 and 6 explore the analytical AI impacts on social and economic domains based on demographic profile. Fig. 5 shows firstly, that the "standard of living" highly influences the respondents' point of view upon the implication of AI on social and economic development as the least scales starting from mostly agree to agree were obtained for that demographic property. This result could be explained by the fact that most respondents have a "moderate standard of living" so that they have a fear of losing their jobs because of AI development.

TABLE III. AI IMPACT ON DOMAINS

\begin{tabular}{|l|l|l|l|l|l|l|}
\hline Domain & \multicolumn{5}{|l|}{ Social } & Economic \\
\hline $\begin{array}{l}\text { Feature } \\
\text { s }\end{array}$ & $\begin{array}{l}\text { Acceptan } \\
\text { ce }\end{array}$ & $\begin{array}{l}\text { Securit } \\
\mathrm{y}\end{array}$ & $\begin{array}{l}\text { Abilit } \\
\mathrm{y}\end{array}$ & $\begin{array}{l}\text { Approv } \\
\text { al }\end{array}$ & $\begin{array}{l}\text { Efficien } \\
\text { cy }\end{array}$ & $\begin{array}{l}\text { Productivi } \\
\text { ty }\end{array}$ \\
\hline Mc & 2.39 & 2.853 & 2.733 & 3.081 & 3.045 & 3.102 \\
\hline $\begin{array}{l}\text { STDEV } \\
\mathrm{c}\end{array}$ & 0.872 & 0.784 & 0.834 & 0.775 & 0.816 & 0.673 \\
\hline Md & 2.82 & & & 3.102 \\
\hline $\begin{array}{l}\text { STDEV } \\
\text { d }\end{array}$ & 0.816 & & 0.673 \\
\hline
\end{tabular}


Secondly, the figure demonstrates also that the "age category" has a strong implication on the respondent's approval criteria as most of the questionnaire participants being between 15 and 34 years old, they have a great curiosity to discover and explore all new AI technologies. As well as Fig. 6 demonstrating that the demographic property "education" has the highest scale (highly agreed) upon AI economic impact, whereas the same property has the least Likert scale (mostly agree) about AI social impact. The result could be explained by the fact that the higher the education level, the higher the respondents' awareness about the influence of AI on society criteria including employment, security, privacy, and poverty.

Generally, from the research results shown in Fig. 4, 5 and 6 , it is clear that almost all respondents are fully in support of the intervention of this technology in their life and their feedbacks reveal that AI has a greater impact on the economic domain than the social domain.

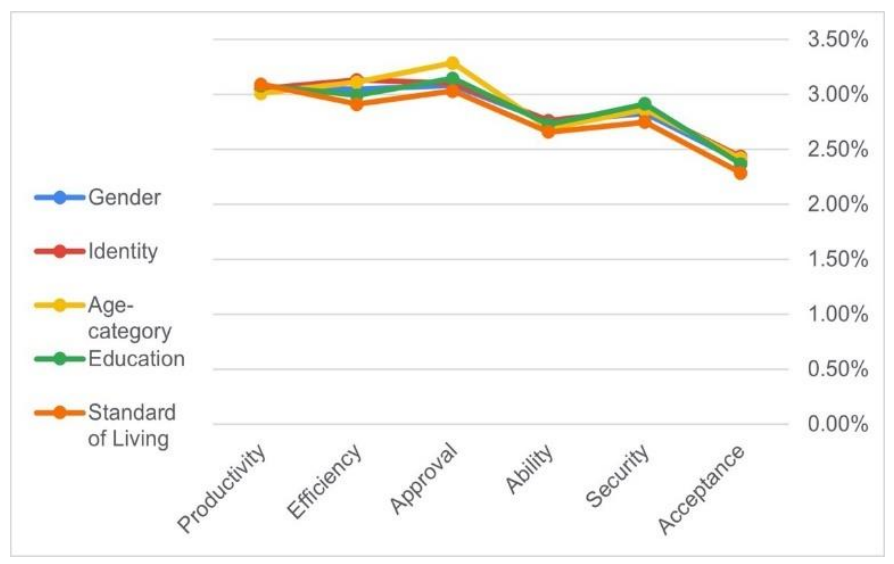

Fig. 4. AI Impacts on Social and Economic Domains.

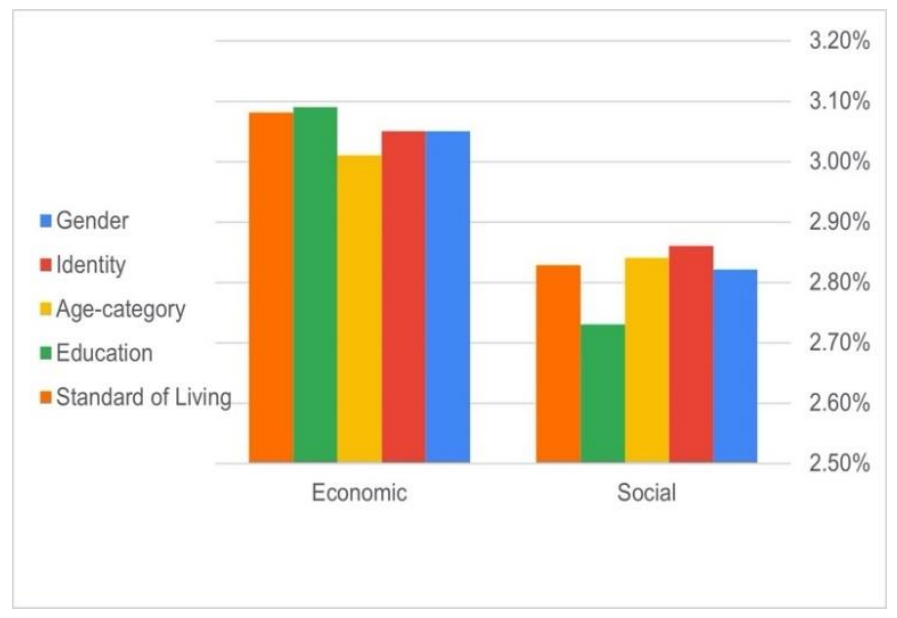

Fig. 5. Distribution of Relation's Perspective between each Domains' Criteria and Demo- Graphic's Profile.

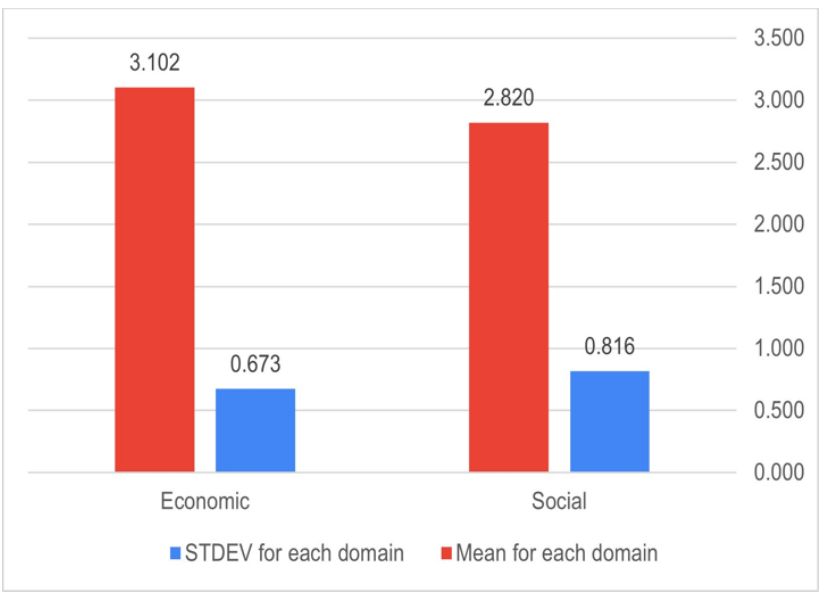

Fig. 6. Distribution of AI Impact on the Relationship between Social, Economic Domains and Demographic's Profile.

\section{CONCLUSion, Future WORK AND Limitations}

As Saudi Arabia continues to diversify away from oil dependence, the Kingdom has adopted a series of procedures considered to be adherent to AI technology. In this paper, the AI implications upon social and economic development have been presented. A special focus on the use of smart cars and smart cameras to monitor intelligently traffic, public services and national security has been studied. Understanding how the Saudi community is reacting during this economic pattern change is a significant challenge for social/economic experts and policymakers. The work outlined in this paper has resulted in evidence-based work, considerable worries of social AI implications, including ethical concerns, job loss and the changing workforce.

Responses also indicate that there is not enough general knowledge of AI, including what it can help accomplish in business and society and the consequences of not implementing it. Therefore, there needs to put in place adequate mechanisms to help companies and government negotiate the social and economic implications of AI. Several issues may be further investigated to highlight the concerns, behaviours and problems of the numerous participants' demographic profile so that we could enhance the social and economic impact of AI in Saudi Arabia.

\section{A. Limitations}

The number of participants in this study is acceptable. Nevertheless, the participation rate could not be calculated for the online questionnaire as the prediction of adherent number for each mobile messaging application is impossible. Furthermore, the questionnaire takes only $2-3$ minutes, and we tried to encourage participants through several ways of official communication. The male contribution was lower than expected due to the difficulty to contact them, as the college was originally devoted to females. Finally, there is no local data addressing matching rate or demographic profile distribution of AI impacts upon social and economic development in Saudi Arabia to compare with. 


\section{ACKNOWLEDGMENT}

This paper is published under the socio-economic Implications of Artificial Intelligence project, as a part of Smart Campus implementation in Imam Abdulrahman bin Faisal University, Community College (CCD). The authors would like to special thanks to the Computer Department for supporting this work by giving the authorisation to share the survey through all students and faculty members.

\section{REFERENCES}

[1] Clark, C. M., \& Gevorkyan, A. V. (2020). Artificial Intelligence and Human Flourishing. American Journal of Economics and Sociology, 79(4), 1307-1344.

[2] E. H. A. Elsaadani, M. Purdy, How Artificial Intelligence can Drive Diversification in the Middle East. Accenture, 2018.

[3] M. Stephens, "Sheikha shamma bint sultan bin khalifa al nahyan and christopher m. schroeder (2019).'perspective - future disruptive governments: Catching up with technological advancements and new horizons', future governments (actions and insights-middle east north africa, vol- ume 7)," 2019.

[4] A. Beg, A. R. Qureshi, T. Sheltami, and A. Yasar, "Uav-enabled intelligent traffic policing and emergency response handling system for the smart city," Personal and Ubiquitous Computing, pp. 1-18, 2020.

[5] D. Impedovo and G. Pirlo, "Artificial intelligence applications to smart city and smart enterprise," 2020.

[6] H. Shokravi, H. Shokravi, N. Bakhary, M. Heidarrezaei, S. S. Rahimian Koloor, and M. Petr, "A review on vehicle classification and potential use of smart vehicle-assisted techniques," Sensors, vol. 20, no. 11, p. 3274, 2020.

[7] Huhtamo, E. (2020). The Self-Driving Car: A Media Machine for Posthumans?. Artnodes, (26), 1-14.

[8] A. Agrawal, J. S. Gans, and A. Goldfarb, "Exploring the impact of artificial intelligence: Prediction versus judgment," Information Economics and Policy, vol. 47, pp. 1-6, 2019.

[9] D. Amodei, C. Olah, J. Steinhardt, P. Christiano, J. Schulman, and D. Mane', "Concrete problems in ai safety," arXiv preprint arXiv:1606.06565, 2016.

[10] E. J. Topol, "High-performance medicine: the convergence of human and artificial intelligence," Nature medicine, vol. 25, no. 1, pp. 44-56, 2019.
[11] K. Arai, "Vital sign and location/attitude monitoring with sensor networks for the proposed rescue system for disabled and elderly persons who need a help in evacuation from disaster areas," sensors, vol. 3 , no. $1,2014$.

[12] L. Amouri, M. Jallouli, C. Novales, G. Poisson, and N. Derbel, "Evaluation of user interface performing a dvz-fuzzy logic pilot for powered wheelchair.," Journal of Automation, Mobile Robotics \& Intelligent Systems, vol. 13, no. 3, 2019.

[13] L. Amouri, C. Novales, M. Jallouli, G. Poisson, and N. Derbel, "An effective dvz-fuzzy logic pilot for a mobile robot using generic architecture," International Journal of Vehicle Autonomous Systems, vol. 12, no. 3, pp. 201-220, 2014.

[14] A. Hussein, M. Adda, M. Atieh, and W. Fahs, "Smart home design for disabled people based on neural networks," Procedia Computer Science, vol. 37, pp. 117-126, 2014.

[15] A. Ghorbel, M. Jallouli, L. Amouri, and N. B. Amor, "A hw/sw implementation on fpga of absolute robot localization using webcam data," Sensors, Circuits \& Instrumentation Systems, vol. 2, p. 75, 2017.

[16] Saveliev, A., \& Zhurenkov, D. (2020). Artificial intelligence and social responsibility: the case of the artificial intelligence strategies in the United States, Russia, and China. Kybernetes.

[17] V. C. Mu"ller and N. Bostrom, "Future progress in artificial intelligence: A survey of expert opinion," in Fundamental issues of artificial intelligence, pp. 555-572, Springer, 2016.

[18] C. B. Frey and M. A. Osborne., "The future of employment: How susceptible are jobs to computerisation?," Mimeo, Oxford Martin School, 2013.

[19] H. J. J. O. E. P. David, "Why are there still so many jobs? the history and future of workplace automation," Journal of economic perspectives, vol. 29, no. 3, pp. 3-30, 2015.

[20] E. Ernst, R. Merola, and D. Samaan, "Economics of artificial intelligence: Implications for the future of work," IZA Journal of Labour Policy, vol. 9, no. 1, 2019.

[21] G. C. Allen, Understanding China's AI Strategy: Clues to Chinese Strategic Thinking on Artificial Intelligence and National Security. Center for a New American Security Washington, DC, 2019.

[22] Huhtamo, E. (2020). The Self-Driving Car: A Media Machine for Posthumans?. Artnodes, (26), 1-14.

[23] O. Hassan, "Artificial intelligence, neom and saudi arabia's economic diversification from oil and gas," The Political Quarterly, vol. 91, no. 1, pp. 222-227, 2020. 